\title{
CUIDADO DO ENFERMEIRO AO PACIENTE COM PÉ DIABÉTICO
}

\section{ARTIGO ORIGINAL}

CUNHA, Amanda Priscilla da ${ }^{1}$

CUNHA, Amanda Priscilla da. Cuidado do enfermeiro ao paciente com pé diabético. Revista Científica Multidisciplinar Núcleo do Conhecimento. Ano. 06, Ed. 12, Vol. 12, pp. 111-126. Dezembro de 2021. ISSN: 2448-0959, Link de acesso: https://www.nucleodoconhecimento.com.br/saude/pe-diabetico,

DOI: 10.32749/nucleodoconhecimento.com.br/saude/pe-diabetico

\section{RESUMO}

Introdução: O pé diabético também denominado por um estado fisiopatológico multifacetado é caracterizado por lesões que surgem a partir dos pés da pessoa com diabetes sem tratamento adequado e cuidados específicos. Estima-se que a incidência da úlcera de pé diabética chega a 6,3\% dos pacientes diabéticos e sua prevalência se aproxima aos 10\%, sendo que as pessoas com baixa condição socioeconômica são as maiores vítimas. Diante desta evidência, o trabalho se norteia na seguinte questão problema: Quais os cuidados que o Enfermeiro desenvolve em pacientes com o pé diabético? Objetivo geral: Evidenciar o cuidado ao pé diabético relacionado com a prática dos enfermeiros. Metodologia: Foi feito uma revisão integrativa da qual se realizou uma busca na Base de Dados Bibliográficas Especializada na área de Enfermagem (BDENF), na Literatura LatinoAmericana e do Caribe em Ciências da Saúde (LILACS) e na Scientific Electronic Library Online (SCIELO) e que resultaram em sete artigos. Resultados: Os estudos evidenciaram como cuidado do enfermeiro ao pé diabético a educação em saúde, a educação continuada e permanente, as técnicas de avaliação ao pé diabético que envolvem os exames físicos e o autocuidado do paciente com os pés diabéticos. Reforça-se que estes cuidados devem ser realizados de forma prioritária pelos

\footnotetext{
${ }^{1}$ Master em Gestão Hospitalar e Sistemas de Saúde, Enfermeira Licenciatura Plena em Enfermagem. ORCID: 000-0001-5456-1848.

RC: 104456

Disponível em: https://www.nucleodoconhecimento.com.br/saude/pe-diabetico
} 
enfermeiros, visto que o enfermeiro tem em suas principais atribuições a assistência específica e qualificada ao paciente. Conclusão: Conclui-se, portanto, que o estudo identificou várias formas de cuidado realizado pelos enfermeiros e que todas estas formas são importantes para a continuidade do tratamento e a prevenção de complicações, contudo, cabe ao enfermeiro ser um profissional que preze a qualidade de sua assistência baseada em conceitos teóricos que conduzam a capacitações frequentes.

Palavras-chave: Cuidado ao paciente, Diabetes Mellitus, Pé diabético.

\section{INTRODUÇÃO}

O Diabetes Mellitus (DM), é uma doença desenvolvida no sistema endócrino e/ou uma desordem metabólica crônica, representando um sério problema de saúde a nível mundial e tem como característica principal a hiperglicemia, chegando a um nível sanguíneo de glicose superior a $126 \mathrm{mg} / \mathrm{dL}$ no jejum ou >200 mg/dL no estágio pós prandial, e que podem ter sido associados a resistência da insulina, secreção inadequada de insulina ou excessiva secreção de glucagon (ASCHNER et al., 2016).

Portanto, a hiperglicemia causa a incapacidade total ou parcial da produção de insulina, segundo a Sociedade Brasileira de Diabetes (SBD), American Diabetes Association (ADA) e Organização Mundial da Saúde (OMS) a DM é dividida em quatro grupos: diabetes Mellitus tipo 1, diabetes Mellitus tipo 2, diabetes Mellitus gestacional e outros tipos específicos de diabetes (OMS, 1999; SBD, 2017; ADA 2017).

A SBD descreve os fatores de risco para o DM, os quais são citados os principais como: diagnóstico de pré-diabetes - diminuição da tolerância à glicose ou glicose de jejum alterada; hipertensão; hipercolesterolemia ou alterações na taxa de triglicérides no sangue; sobrepeso e obesidade, principalmente se a gordura estiver concentrada em volta da cintura; história familiar; bebê com peso superior a quatro quilos ou diabetes gestacional; síndrome de ovários policísticos; diagnóstico de 
alguns distúrbios psiquiátricos, como esquizofrenia, depressão, transtorno bipolar e uso de medicações psicotrópicas; entre outros (SBD, 2018).

Por se constituir uma doença que afeta aproximadamente $3 \%$ da população mundial e com uma prevalência aproximada de $6,2 \%$ da população do Brasil, cuja mesma é aumentada dado o envelhecimento populacional (MUZY et al., 2021), a DM tem causado uma oneração nos cofres públicos, além de também possibilitar altos custos para realizar o tratamento de suas complicações como: pé diabético, doenças cardiovasculares, amputação e outros. Vale ressaltar que o tratamento farmacológico vem obtendo avanços para o controle do DM, todavia, a educação em saúde como forma de prevenção deve ser transmitida a população geral de modo individual ou grupal enfatizando a problemática da doença e seus prejuízos à saúde (SILVA, 2018).

Quanto as complicações do DM, o pé diabético também é denominado por seu estado fisiopatológico multifacetado, caracterizado por lesões que surgem a partir dos pés da pessoa com diabetes provenientes da neuropatia em $90 \%$ dos casos, em que a doença vascular periférica e as deformidades são predominantes (CUBAS et al., 2017).

De Sousa Mendonça; Moraes; Moura (2017) descreve que as lesões existentes no pé diabético são provenientes da combinação entre dois ou mais fatores de risco que podem estar relacionados a traumas intrínsecos como extrínsecos, associados à neuropatia periférica causando a perda da sensibilidade facilitando para o risco de cortes; doença vascular periférica resultante da redução do fluxo sanguíneo nos membros inferiores e alteração biomecânica que acontece quando se tem a restrição de movimentos das articulações do pé e do tornozelo.

Estima-se que a incidência da úlcera de pé diabética chega a 6,3\% dos pacientes diabéticos e sua prevalência se aproxima aos $10 \%$, sendo que as pessoas com baixa condição socioeconômica são as maiores vítimas. A amputação do pé diabético é outra problemática e que a nível mundial a cada três minutos uma pessoa tem seu membro amputado devido ao DM (ARRUDA et al., 2021). 
O bom gerenciamento de fatores que estão envolvidos na etiologia da lesão existente no pé diabético se torna eficaz quando realizado pelo enfermeiro, para tanto o mesmo deve estar capacitado e qualificado a realizar a consulta de enfermagem de modo a desvelar as alterações dermatológicas, musculoesqueléticas, vasculares e neurológicas no pé diabético (FÉLIX et al., 2021).

Portanto, os cuidados aos pés diabéticos se tornam deveras importante dentro da saúde pública e o enfermeiro como profissional que tem em sua premissa o cuidado ao paciente, deve estar atento e qualificado quanto às novas formas de tratamento para redução de amputações. Frente a este cenário de índices alarmantes, torna-se imprescindível uma observação de como o enfermeiro está situado nas práticas ao cuidado no pé diabético.

Diante desta evidência que envolve números alarmantes em relação ao pé diabético, o trabalho se norteia na seguinte questão problema: Quais os cuidados que o Enfermeiro desenvolve em pacientes com o pé diabético?

O estudo em questão tem como objetivo evidenciar o cuidado ao pé diabético relacionado com a prática dos enfermeiros.

\section{METODOLOGIA}

Para este estudo foi realizado uma revisão integrativa da literatura. De acordo com Mendes; Silveira e Galvão (2019), o método de revisão integrativa é desenvolvido seguindo etapas bem definidas; são elas: identificação do tema e seleção da questão norteadora; estabelecimento dos critérios de inclusão e exclusão; identificação dos estudos pré-selecionados e selecionados; categorização dos estudos selecionados; análise e interpretação dos resultados e apresentação da síntese da revisão.

O primeiro passo da revisão integrativa é a questão norteadora, e que conduz ao tema e aos objetivos elencados. Portanto, a pergunta que surge neste artigo é: Quais os cuidados que o Enfermeiro desenvolve em pacientes com o pé diabético? 
Para estabelecer os critérios de inclusão foram utilizados: artigos publicados e disponíveis para leitura, como o assunto reflete o enfermeiro em suas atribuições, foi escolhido o Banco de dados da BDENF, LILACS e SCIELO, a delimitação temporal ficou nos anos de 2016 a 2020, ou seja, nos últimos cinco anos, e, a língua portuguesa foi à escolhida para esta inclusão.

Para os critérios de exclusão foram retirados: artigos que tenham duplicidade, artigos incompletos, anais, textos de opinião, editoriais e cartas ao leitor, artigos de revisão, teses, dissertações, textos completos, mas que não se relacionem ao tema.

O período da coleta de dados correspondeu ao mês de setembro de 2021. Os descritores nacionais identificados foram: "assistência de enfermagem", "pé diabético", "Enfermeiro", "diabetes mellitus". O operador booleano and foi utilizado para associar os descritores na estratégia de busca na plataforma dos bancos de dados.

Para a seleção dos estudos selecionados e pré-selecionados foi feita uma leitura minuciosa dos títulos e resumos dos artigos encontrados, e logo em seguida uma leitura mais completa em todo o artigo, procurando em seus resultados a identificação para o alcance do objetivo proposto neste artigo.

Foram realizadas duas buscas a primeira utilizou a seguinte estratégia de busca: assistência de enfermagem and pé diabético and diabetes mellitus, com esta estratégia foram encontrados 186 artigos. Após utilizar os filtros: texto completo e disponível, base de dados, língua portuguesa e delimitação temporal dos últimos cinco anos, restaram 24 artigos para elegibilidade. A segunda busca foi feita com a seguinte estratégia: enfermeiro and pé diabético encontrando 95 artigos. Após a utilização dos filtros restaram 11 artigos para a elegibilidade.

Os estudos foram categorizados a partir de um quadro sinóptico e a análise e apresentação dos resultados foi conduzida após a categorização a qual identificou e definiu os núcleos de sentidos dos estudos, e que a partir da análise temática de Minayo (2012), teve a discussão entre os autores encontrados. 
Para a síntese de conhecimento, foi feito uma análise das limitações, da representatividade do estudo para a comunidade em geral (relevância) e estudos futuros identificados no decorrer deste artigo. Todas as produções utilizadas neste estudo estão rigorosamente referenciadas de acordo com as normas da Associação Brasileira de Normas Técnicas (ABNT).

\section{RESULTADOS E DISCUSSÕES}

Os artigos que restaram para a elegibilidade com as duas estratégias somaram 35 artigos. Inicialmente foram retirados artigos de revisão, trabalhos de conclusão de curso, cartas ao leitor, relatos de experiência, estudos de caso, artigos duplicados e que em seus títulos, resumos e leitura na íntegra não trouxessem o enfermeiro e sua assistência como temática ao assunto, restando assim 07 artigos para esta revisão.

Para uma melhor ilustração dos resultados encontrados o quadro a seguir contemplará a caracterização dos estudos selecionados. Os dados são referentes à: título do artigo, ano de publicação, base de dados, periódico, Local, objetivo e resultados.

Quadro 1. Artigos encontrados na base de dados BDENF, LILACS e SCIELO sobre cuidado do enfermeiro ao paciente com pé diabético.

\begin{tabular}{|c|c|c|c|c|c|}
\hline $\begin{array}{l}\text { Título/ Ano de } \\
\text { publicação }\end{array}$ & $\begin{array}{l}\text { Base } \\
\text { de } \\
\text { dados }\end{array}$ & $\begin{array}{l}\text { Periódic } \\
0\end{array}$ & Objetivo & Local & Resultados \\
\hline $\begin{array}{l}\text { Conheciment } \\
0 \text { do } \\
\text { enfermeiro } \\
\text { acerca dos } \\
\text { cuidados com } \\
\text { o pé diabético } \\
2019\end{array}$ & BDENF & $\begin{array}{l}\text { Rev. } \\
\text { enferm. } \\
\text { UFPE } \\
\text { on line }\end{array}$ & $\begin{array}{l}\text { Compreender } \\
\text { o } \\
\text { conhecimento } \\
\text { do enfermeiro } \\
\text { acerca dos } \\
\text { cuidados com } \\
\text { os pés de } \\
\text { diabéticos na }\end{array}$ & $\begin{array}{l}\text { Estratégia } \\
\text { Saúde da } \\
\text { Família/ESF }\end{array}$ & $\begin{array}{l}\text { Realizar } \\
\text { periodicament } \\
\text { e o exame } \\
\text { físico dos pés } \\
\text { em } \\
\text { diabéticos; } \\
\text { Utilização de } \\
\text { instrumentos }\end{array}$ \\
\hline
\end{tabular}




\begin{tabular}{|c|c|c|c|c|c|}
\hline & & & $\begin{array}{l}\text { Atenção } \\
\text { Primária }\end{array}$ & & $\begin{array}{l}\text { para } \\
\text { avaliação do } \\
\text { pé diabético } \\
\text { Auto-cuidado } \\
\text { aos pés }\end{array}$ \\
\hline $\begin{array}{l}\text { Riscos } \\
\text { associados à } \\
\text { mortalidade } \\
\text { em pacientes } \\
\text { atendidos em } \\
\text { um programa } \\
\text { de prevenção } \\
\text { do pé } \\
\text { diabético } \\
2018\end{array}$ & $\begin{array}{l}\text { LILACS } \\
/ \\
\text { BDENF }\end{array}$ & $\begin{array}{l}\text { Rev. } \\
\text { gaúch. } \\
\text { enferm }\end{array}$ & $\begin{array}{l}\text { Identificar em } \\
\text { pacientes com } \\
\text { diabetes tipo } 2 \\
\text { quais } \\
\text { alterações nos } \\
\text { pés estariam } \\
\text { associadas às } \\
\text { características } \\
\text { demográficas, } \\
\text { clínicas, } \\
\text { bioquímicas e } \\
\text { de tratamento } \\
\text { e quais delas } \\
\text { aumentariam o } \\
\text { risco de } \\
\text { mortalidade }\end{array}$ & $\begin{array}{l}\text { Programa } \\
\text { educativo de } \\
\text { prevenção e } \\
\text { tratamento } \\
\text { do pé } \\
\text { diabético em } \\
\text { um hospital } \\
\text { geral alta } \\
\text { universitário } \\
\text { de complexidad } \\
\text { e }\end{array}$ & $\begin{array}{l}\text { Educação em } \\
\text { saúde sobre } \\
\text { higiene dos } \\
\text { pés, a } \\
\text { escolha dos } \\
\text { calçados } \\
\text { apropriados, } \\
\text { a melhor } \\
\text { conduta em } \\
\text { situações de } \\
\text { emergência. } \\
\text { Cuidados } \\
\text { sistêmicos } \\
\text { como não } \\
\text { fumar, manter } \\
\text { um bom } \\
\text { controle } \\
\text { glicêmico, } \\
\text { controlar as } \\
\text { taxas dipídios } \\
\text { sanguíneas e } \\
\text { o uso correto } \\
\text { dos } \\
\text { medicamento } \\
\text { s }\end{array}$ \\
\hline
\end{tabular}




\begin{tabular}{|c|c|c|c|c|c|}
\hline $\begin{array}{l}\text { Condutas dos } \\
\text { enfermeiros } \\
\text { da atenção } \\
\text { primária no } \\
\text { cuidado a } \\
\text { pessoas com } \\
\text { pé diabético } \\
2017\end{array}$ & BDENF & $\begin{array}{l}\text { Rev. } \\
\text { enferm. } \\
\text { UFPE } \\
\text { on line }\end{array}$ & 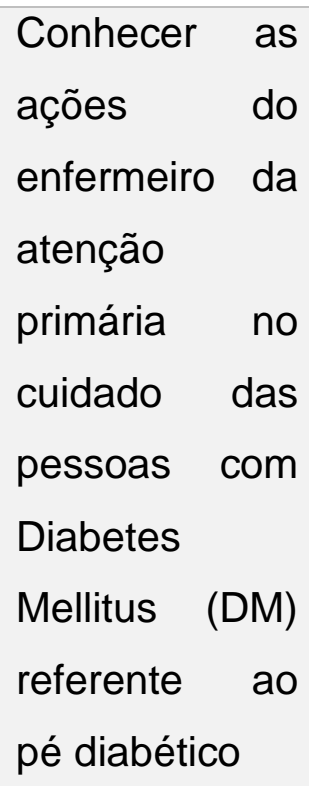 & $\begin{array}{l}\text { Estratégia de } \\
\text { Saúde da } \\
\text { Família }\end{array}$ & $\begin{array}{l}\text { Frequência e } \\
\text { agendamento } \\
\text { das } \\
\text { consultas, } \\
\text { dinâmicas de } \\
\text { atendimento, } \\
\text { critérios para } \\
\text { a realização } \\
\text { do exame dos } \\
\text { pés, } \\
\text { autocuidado }\end{array}$ \\
\hline $\begin{array}{l}\text { Ações do } \\
\text { enfermeiro na } \\
\text { prevenção do } \\
\text { pé diabético: } \\
0 \text { olhar da } \\
\text { pessoa com } \\
\text { diabetes } \\
\text { mellitus } \\
2017\end{array}$ & $\begin{array}{l}\text { LILACS } \\
/ \\
\text { BDENF }\end{array}$ & $\begin{array}{l}\text { Rev. } \\
\text { Pesqui. } \\
\text { (Univ. } \\
\text { Fed. } \\
\text { Estado } \\
\text { Rio J., } \\
\text { Online) }\end{array}$ & $\begin{array}{l}\text { Investigar as } \\
\text { ações } \\
\text { realizadas pelo } \\
\text { enfermeiro na } \\
\text { prevenção do } \\
\text { pé diabético } \\
\text { na perspectiva } \\
\text { da pessoa } \\
\text { com DM. }\end{array}$ & $\begin{array}{l}\text { Projeto de } \\
\text { extensão da } \\
\text { Universidade }\end{array}$ & $\begin{array}{l}\text { Ações } \\
\text { específicas, } \\
\text { que envolvem } \\
\text { propriamente } \\
\text { o exame dos } \\
\text { pés, diálogo } \\
\text { comunicativo, } \\
\text { educação em } \\
\text { saúde. }\end{array}$ \\
\hline $\begin{array}{l}\text { Alterações } \\
\text { nos pés do } \\
\text { idoso } \\
\text { hospitalizado: } \\
\text { um olhar } \\
\text { cuidadoso da } \\
\text { enfermagem } \\
2017\end{array}$ & $\begin{array}{l}\text { LILACS } \\
/ \\
\text { BDENF }\end{array}$ & $\begin{array}{l}\text { Esc. } \\
\text { Anna } \\
\text { Nery } \\
\text { Rev. } \\
\text { Enferm }\end{array}$ & $\begin{array}{l}\text { Caracterizar o } \\
\text { perfil } \\
\text { podológico de } \\
\text { idosos } \\
\text { hospitalizados } \\
\text { nas } \\
\text { enfermarias de } \\
\text { um hospital } \\
\text { universitário; } \\
\text { identificar as } \\
\text { demandas de }\end{array}$ & Hospital & $\begin{array}{l}\text { Fortaleciment } \\
\text { o dos } \\
\text { vínculos com } \\
\text { esses } \\
\text { pacientes } \\
\text { diabéticos } \\
\text { para que } \\
\text { estes venham } \\
\text { ao posto com } \\
\text { frequência } \\
\text { realizar os }\end{array}$ \\
\hline
\end{tabular}




\begin{tabular}{|c|c|c|c|c|c|}
\hline & & & $\begin{array}{l}\text { cuidados com } \\
\text { os pés de } \\
\text { pacientes } \\
\text { idosos } \\
\text { hospitalizados; } \\
\text { e analisar as } \\
\text { possibilidades } \\
\text { de atuação do } \\
\text { enfermeiro } \\
\text { junto a esses } \\
\text { idosos. }\end{array}$ & & $\begin{array}{l}\text { exames nos } \\
\text { pés } \\
\text { Capacitação } \\
\text { e qualificação } \\
\text { para assistir a } \\
\text { esses } \\
\text { problemas, } \\
\text { evitando } \\
\text { maiores } \\
\text { complicações } \\
\text { e diminuindo } \\
\text { as demandas } \\
\text { futuras de } \\
\text { cuidado }\end{array}$ \\
\hline $\begin{array}{l}\text { Atuação dos } \\
\text { enfermeiros } \\
\text { da estratégia } \\
\text { saúde da } \\
\text { família na } \\
\text { prevenção do } \\
\text { pé diabético } \\
2016\end{array}$ & $\begin{array}{l}\text { LILACS } \\
/ \\
\text { BDENF }\end{array}$ & $\begin{array}{l}\text { Rev. } \\
\text { Pesqui. } \\
\text { (Univ. } \\
\text { Fed. } \\
\text { Estado } \\
\text { Rio J., } \\
\text { Online) ; }\end{array}$ & 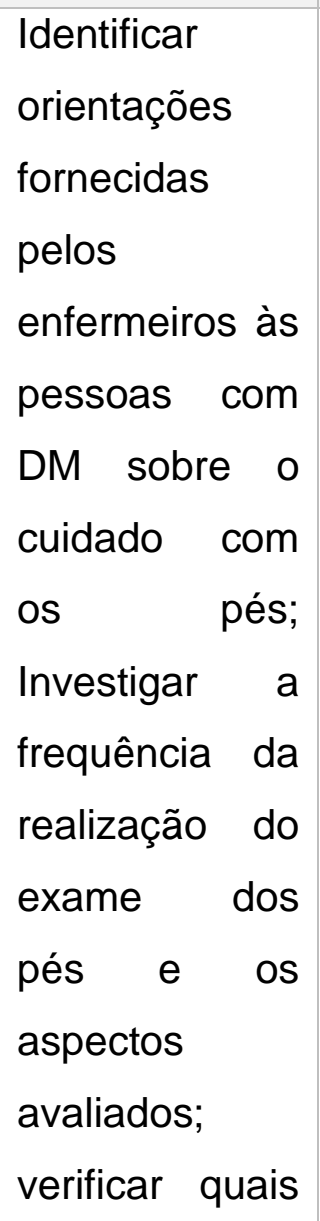 & $\begin{array}{l}\text { Estratégia } \\
\text { Saúde da } \\
\text { Família }\end{array}$ & $\begin{array}{l}\text { Educação em } \\
\text { saúde para os } \\
\text { diabéticos, } \\
\text { exame dos } \\
\text { pés das } \\
\text { pessoas com } \\
\text { DM, } \\
\text { Formação de } \\
\text { grupos de } \\
\text { convivência, } \\
\text { realização de } \\
\text { curativos em } \\
\text { técnicas } \\
\text { adequadas ao } \\
\text { tipo de lesão } \\
\text { no pé. }\end{array}$ \\
\hline
\end{tabular}




\begin{tabular}{|c|c|c|c|c|c|}
\hline & & & $\begin{array}{l}\text { atividades de } \\
\text { educação em } \\
\text { saúde é } \\
\text { realizado pelos } \\
\text { enfermeiros } \\
\text { para as } \\
\text { pessoas com } \\
\text { DM. }\end{array}$ & & \\
\hline $\begin{array}{l}\text { A perspectiva } \\
\text { da } \\
\text { vulnerabilidad } \\
\text { e na } \\
\text { avaliação do } \\
\text { pé diabético } \\
\text { sob a ótica de } \\
\text { enfermeiros } \\
2016\end{array}$ & BDENF & $\begin{array}{l}\text { Cogitare } \\
\text { enferm }\end{array}$ & $\begin{array}{l}\text { Escrever as } \\
\text { condições } \\
\text { determinantes } \\
\text { sociais em } \\
\text { saúde, } \\
\text { identificadas } \\
\text { por } \\
\text { enfermeiros } \\
\text { como } \\
\text { relevantes } \\
\text { para } \\
\text { estabeleciment } \\
\text { o de } \\
\text { vulnerabilidade } \\
\text { s da pessoa } \\
\text { com Diabetes } \\
\text { Mellitus. }\end{array}$ & $\begin{array}{l}\text { Enfermeiros } \\
\text { escolhidos } \\
\text { aleatoriament } \\
\text { e em Curitiba }\end{array}$ & $\begin{array}{ll}\text { Estimular } & \text { o } \\
\text { diabético a ir } \\
\text { para } \\
\text { avaliação } \\
\text { nutricional e } \\
\text { acompanhar } \\
\text { dieta. }\end{array}$ \\
\hline
\end{tabular}

Fonte: Autor.

O estudo em seus objetivos mencionam três tipos de cuidado executados pelo enfermeiro para o paciente com pé diabético: $O$ primeiro que mais surgiu se baseia nas ações voltadas à educação em saúde como princípio fundamentador da prevenção da doença e de suas complicações, o segundo cuidado baseia-se nas 
técnicas de avaliação dos pés nos diabéticos como forma de surgimento de complicações e o terceiro cuidado tem como foco o enfermeiro como estimulador e motivador dos pacientes diabético ao seu autocuidado com os pés. Estes três cuidados serão discutidos em suas temáticas conforme os estudos selecionados.

\subsection{A EDUCAÇÃO EM SAÚDE COMO FORMA DE PREVENÇÃO}

Portanto, a partir da educação em saúde, o paciente consegue entender as razões pelas quais o processo de cicatrização da ferida é lento, os motivos das principais complicações e principalmente o conhecimento relacionado à prevenção de riscos. O enfermeiro deve saber reconhecer as necessidades do paciente e assim contribuir para que sejam dados diagnósticos de enfermagem precisos e seguros relacionados à ferida em seu estágio.

Scain; Franzen; Hirakata (2018) relatam que o enfermeiro vem mantendo esforços para realizar educação em saúde com os pacientes, tornando-se persistente e insistente para dar continuidade ao processo educativo em pacientes com pés diabéticos, usam da criatividade com a elaboração de tecnologias educativas como folders, vídeos, bem como se disponibilizam para tirar dúvidas sobre alguma condição anormal com o paciente a partir de tecnologias das mídias sociais como Whatsapp/telefone.

Camillo et al. (2016) menciona que o conceito de educação em saúde vai além de trazer dados ou mesmo retirar dúvidas que surgem, os autores consideram a educação em saúde um processo sistemático, contínuo e permanente, objetivando a formação e o desenvolvimento da consciência crítica do cidadão, através da busca de soluções coletivas para os problemas vivenciados e a sua "participação real" no exercício do controle social.

Vargas et al. (2017) traz a educação em saúde como uma das principais finalidades das atribuições do enfermeiro para o cuidado, os autores reforçam que a educação em saúde favorece ao paciente uma postura mais proativa, demonstrando que o paciente deve ter segurança sobre o cuidar do pé diabético. 
A autonomia e segurança ao cuidado também foram apontadas como resultados das educações em saúde realizada por enfermeiros no estudo de Pereira et al. (2017), os autores referem que a educação em saúde se torna o principal mecanismo de prevenção contra doenças e suas complicações, em relação ao pé diabético, a educação em saúde promove ao paciente segurança, confiança e autonomia.

A demonstração que a educação em saúde é eficaz foi identificada em um estudo descritivo de abordagem quantitativa em que evidenciou que a educação em saúde trouxe aos pacientes um conhecimento teórico sobre a doença respeitando a cultura e crença dos pacientes, e que a promoção dos processos educativos se dá não somente em conjunto, mas de forma individualizada, tirando as dúvidas que permeiam o paciente durante a consulta de enfermagem ou mesmo em um diálogo informal entre paciente e o profissional (DE OLIVEIRA et al., 2016).

Mas a educação em saúde não é somente identificada como processo de cuidado aos pacientes, os enfermeiros devem também estar atentos às capacitações e qualificações, o que também pode ser considerado uma educação em saúde de forma mais técnica. Silva; Santo e Chibante (2017) refere que o enfermeiro deve estar sempre atualizado para as novas formas de cuidar do pé diabético, já que os processos de tratamento estão cada vez mais sendo estudados na literatura científica e trazem inovações para a cura ou mesmo estadiamento da ferida.

Portanto, a educação em saúde, a educação continuada e a educação permanente são formas de cuidar que os enfermeiros utilizam em prol de melhorar o quadro clínico do paciente com o pé diabético.

\subsection{TÉCNICAS DE AVALIAÇÃO DOS PÉS DIABÉTICOS}

O saber técnico-científico adquirido durante as fases de formação do enfermeiro e no contexto da educação continuada e permanente são fatores relevantes para o tratamento do pé diabético, portanto, cabe ao enfermeiro buscar conhecimentos para realizar técnicas seguras de avaliação ao paciente com diabetes como método 
de prevenção e ao paciente com pé diabético como medidas de prevenção para complicações.

Arruda et al. (2019) refere que o exame físico dos pés diabéticos são procedimentos realizados pelo enfermeiro afim de evitar possíveis complicações como: desenvolvimento de úlceras e amputações dos membros inferiores. Portanto, o desconhecimento desta técnica induz as taxas maiores de complicações. Os autores referenciados apontam em outro momento que além da técnica não ser utilizada por falta conhecimento do enfermeiro, as condições de trabalho também influenciam a não realização da técnica de avaliação, estas condições são referidas pelos autores como infraestrutura inadequada e demanda de atendimento excessivo.

Vargas et al. (2017) traz em seu estudo um contexto semelhante ao estudo anteriormente citado e acrescenta que os enfermeiros necessitam de mais capacitações quanto às técnicas de avaliação relacionadas ao pé diabético, os enfermeiros também referem que a gestão não oferece materiais para executar estas técnicas e falam das demandas excessivas.

Pereira et al. (2017) considera que ações específicas devem ser feitas para remodelar o sistema de atendimento aos pacientes com pé diabético, estas ações devem estar relacionadas além do exame aos pés, apresentando uma comunicação efetiva e a educação em saúde.

Leal et al. (2016) considera que o enfermeiro pode ter desconhecimento do assunto devido a vários fatores e um deles é apontado pelos autores como a alta demanda de atendimento. Esta demanda implica em desgaste físico e mental do profissional o que proporciona uma falta de tempo para a qualificação profissional. Em outro sentido, os autores mencionam que a demanda excessiva de um determinado problema proporciona o profissional a dar espaço para a educação permanente em saúde, em que este tipo de capacitação propõe transformações nas práticas profissionais baseada em problemas existentes no processo de seu trabalho aprendendo a refletir a prática dentro de sua realidade. 
A enfermagem carrega consigo a função de tratar as doenças da pele e seus adjacentes. Isto porque o enfermeiro tem em suas atribuições o cuidar do paciente e a necessidade de ampliar este cuidado associado às doenças relacionadas à pele (DA SILVA BRANDAO et al., 2016; SA et al., 2016).

\subsection{O ENFERMEIRO MEDIADOR PARA O AUTOCUIDADO AO PACIENTE COM PÉ DIABÉTICO}

Falar em autocuidado remete a toda e qualquer ação proveniente do ato diário do ser humano. Quanto ao autocuidado Arruda et al. (2019) relatam que os pacientes com pé diabético tendem a gerar um grande impacto econômico, social, cultural, emocional e biológico, o que favorece a uma maior dependência de outros para auxílio nas atividades de vida diário e uma repercussão no seu autocuidado e qualidade de vida.

Scain; Franzen e Hirakata (2018) relatam que o paciente deve estar ciente a realização de suas próprias atividades e que o autocuidado deve ser contínuo, uma das formas de fazer a realização do autocuidado citados pelos autores foram: Higienização dos pés; escolha de calçados apropriados; evitar andar descalço e outros.

Para Vargas et al. (2017) traz como autocuidado a manutenção do controle glicêmico, a participação proativa dos pacientes na realização dos exames dos pés, a terapêutica, restrição absoluta ao uso de fumo e bebidas, a nutrição o exercício físico, a atividade física e outras formas que contemplam o estudo referenciado anteriormente.

Uma forma de conseguir que o paciente possa almejar o autocuidado é citado pelos autores Silva; Santo e Chibante (2017) como o fortalecimento de vínculos entre o paciente e profissional de saúde. Este fortalecimento favorece a segurança e a credibilidade ao paciente de que realizando de forma contínua e sistemática o autocuidado aos pés, menores são as chances de risco a complicações. 
A autonomia e a segurança demonstrada pelo paciente com pé diabético minimizam danos e riscos de complicações. Um paciente que é envolvido no tratamento de sua doença tende a ampliar seus conhecimentos para a não dependência de outras pessoas, articulando em suas atividades o autocuidado como forma de motivação e de demonstração de capacidade frente às adversidades que envolvem o processo saúde-doença (DE OLIVEIRA et al., 2016).

Para Fátima Bento et al. (2016), o paciente com pé diabético já sofre estigmas provenientes de sua condição o que dificulta que este possa ter um adequado atendimento, isto porque as condições que envolvem distanciamento da unidade de saúde, dificuldades em mobilizar-se, pouco conhecimento sobre a doença, possibilitam a um cuidado inadequado e evolução de complicações.

Contudo, Nascimento et al. (2016) mencionam que quando se tem uma atenção qualificada e humanizada através de condutas eficazes, com fácil acesso aos serviços de saúde a que possam integrar todas as ações em todos os níveis da atenção, o autocuidado sem risco de complicações.

\section{CONCLUSÃO}

Este estudo refletiu sobre os cuidados do enfermeiro quanto profissional na realização do atendimento e assistência ao paciente com pé diabético. Foram identificados nos estudos cuidados relevantes o que conduziu a realização de três temáticas para a discussão dos resultados encontrados.

Sobre o objetivo do estudo apontava em evidenciar os cuidados prestados ao enfermeiro ao paciente com pé diabético, ressalta-se que foi enfatizado exclusivamente cuidados dos enfermeiros e não de outras categorias da enfermagem. Os estudos demonstraram a educação em saúde como primeiro cuidado o que não se pode contrariar, visto que a literatura enfatiza que a educação em saúde é primordial para a prevenção de doenças. 
Outro tipo de cuidado se reflete aos saberes do próprio profissional sobre o pé diabético, de extrema necessidade e grande preocupação no âmbito do sistema de saúde, visto que, os artigos trouxeram reflexões que os enfermeiros devem estar mais qualificados para direcionar um cuidado com mais excelência ao paciente.

Um cuidado importante também apontado pelos estudos e que se direciona de forma direta com a educação permanente ou continuada dos profissionais são as técnicas do exame físico, neste tipo de cuidado, o enfermeiro deve estar apto a realizar o exame dos pés diabéticos com sabedoria e segurança, além de também estimular os pacientes a irem ao exame com mais frequência.

Quanto ao cuidado relacionado ao próprio autocuidado do paciente foi refletido que a higiene dos pés, o controle glicêmico, o acompanhamento contínuo com o exame dos pés, o uso de calcados apropriados e outros intensificam uma prevenção maior contra as complicações entre elas a amputação de membros.

Conclui-se, portanto, que o estudo identificou várias formas de cuidado realizado pelos enfermeiros e que todas estas formas são importantes para a continuidade do tratamento e a prevenção e complicações, contudo, cabe ao enfermeiro ser um profissional que preze a qualidade de sua assistência baseada em conceitos teóricos que conduzam a capacitações frequentes.

\section{REFERÊNCIAS}

AMERICAN DIABETES ASSOCIATION. Standards of medical care in diabetes. Diabetes Care, v. 40, n. suppl 1, p. s1-s128, 2017.

ARRUDA, Cecilia et al. Tecnologia educativa para cuidados e prevenção do pé diabético/Educational technology for care and prevention of diabetic foot ulcers. Ciência, Cuidado e Saúde, v. 20, 2021.

ARRUDA, Luana Savana Nascimento de Sousa et al. Conhecimento do enfermeiro acerca dos cuidados com o pé diabético. Rev. enferm. UFPE on line, p. [1-8], 2019. 
ASCHNER M, Pablo et al. Clinical practice guideline for the prevention, early detection, diagnosis, management and follow up of type 2 diabetes mellitus in adults. Colomb. Med., Cali, v. 47, n. 2, p. 109-130, junho. 2016.

CAMILLO, Bibiana Schultz et al. Ações de educação em saúde na atenção primária a gestantes e puérperas: revisão integrativa. Revista de enfermagem UFPE on line-ISSN: 1981-8963, v. 10, n. 6, p. 4894-4901, 2016.

CUBAS, Marcia Regina et al. Pé diabético: orientações e conhecimento sobre cuidados preventivos. Fisioterapia em movimento, v. 26, n. 3, 2017.

DE FÁTIMA BENTO, Leandra et al. A perspectiva da vulnerabilidade na avaliação do pé diabético sob a ótica de enfermeiros. Cogitare Enfermagem, v. 21, n. 1, 2016.

DE OLIVEIRA, Patrícia Simplício et al. Atuação dos enfermeiros da Estratégia Saúde da Família na prevenção do pé diabético Practice nurse family health strategy in the prevention of diabetic foot. Revista de Pesquisa Cuidado é Fundamental Online, v. 8, n. 3, p. 4841-4849, 2016.

DE SOUZA MENDONÇA, Sarah; MORAIS, Juliana de Sant'Anna; DE MOURA, Maria Catarina Gomes Gadelha. Proposta de um protocolo de avaliação fisioterapêutica para os pés de diabéticos. Fisioterapia em Movimento, v. 24, n. 2, 2017.

FELIX, Lidiany Galdino et al. Conhecimento de enfermeiros da atenção primária antes e após intervenção educativa sobre pé diabético. Revista Gaúcha de Enfermagem, v. 42, 2021.

LEAL, Maria do Carmo et al. Atenção ao pré-natal e parto em mulheres usuárias do sistema público de saúde residentes na Amazônia Legal e no Nordeste, Brasil 2010. Rev. Bras. Saude Mater. Infant. Recife, v. 15, n. 1, p. 91-104, Mar. Available from \&lt; http://www.scielo.br/scielo.php?script=sci_arttext\&amp;pid=S1519$38292015000100091 \& a m p ;$ Ing=en\&amp;nrm=iso\&gt;. 
MENDES, Karina Dal Sasso; SILVEIRA, Renata Cristina de Campos Pereira; GALVÃO, Cristina Maria. Uso de gerenciador de referências bibliográficas na seleção dos estudos primários em revisão integrativa. Texto \& ContextoEnfermagem, v. 28, 2019.

MINAYO, Maria Cecília de Souza. Análise qualitativa: teoria, passos e fidedignidade. Ciência \& saúde coletiva, v. 17, p. 621-626, 2012.

MUZY, Jéssica et al. Prevalência de diabetes mellitus e suas complicações e caracterização das lacunas na atenção à saúde a partir da triangulação de pesquisas. Cadernos de Saúde Pública, v. 37, 2021.

NASCIMENTO, Vagner Ferreira do et al. Percepção de puérperas sobre as primeiras consultas de pré-natal no interior de Mato Grosso. Rev. enferm. UFPI, v.5, n. 1, p. 46-51, 2016.

ORGANIZAÇÃO MUNDIAL DE SAÚDE. Definition, diagnosis and classification of diabetes Mellitus and its complications. Geneva: OMS, 1999. Disponível em: https://apps.who.int/iris/bitstream/handle/10665/66040/WHO_NCD_NCS_99.2.pdf?s equence $=1$ \&isAllowed $=\mathrm{y}$

PEREIRA, Laiane de Fátima et al. Ações do enfermeiro na prevenção do pé diabético: o olhar da pessoa com diabetes mellitus. Rev. pesqui. cuid. fundam. (Online), p. 1008-1014, 2017.

SCAIN, Suzana Fiore; FRANZEN, Elenara; HIRAKATA, Vânia Naomi. Riscos associados à mortalidade em pacientes atendidos em um programa de prevenção do pé diabético. Revista Gaúcha de Enfermagem, v. 39, 2018.

SILVA, Caline Oliveira da. Análise da qualidade de vida em indivíduos com Diabetes Mellitus Tipo 1. 2017. $34 \mathrm{f}$. Trabalho de conclusão de curso (Bacharelado em Farmácia) -Universidade de Brasília, Brasília, 2017. Disponível em: https://bdm.unb.br/handle/10483/19301 
SILVA, Joziane Santos da; SANTO, Fátima Helena do Espírito; CHIBANTE, Carla Lube de Pinho. Alterações nos pés do idoso hospitalizado: um olhar cuidadoso da enfermagem. Escola Anna Nery, v. 21, 2017.

SOCIEDADE BRASILEIRA DE DIABETES. Tratamento e acompanhamento do diabetes Mellitus: Diretrizes da Sociedade Brasileira de Diabetes. 3.ed. Itapevi, SP: A. Araújo Silva Farmacêutica; 2017/2018. Disponível em: http://www.diabetes.org.br/ profissionais/images/2017/diretrizes/diretrizes-sbd-20172018.pdf.

VARGAS, Caroline Porcelis et al. Condutas dos enfermeiros da atenção primária no cuidado a pessoas com pé diabético. Rev. enferm. UFPE on line, p. 4535-4545, 2017.

Enviado: Outubro, 2021.

Aprovado: Dezembro, 2021. 